\title{
BROOD PARASITISM INCREASES MORTALITY OF BAY-WINGED COWBIRD NESTS
}

\author{
María C. De Mársico ${ }^{1}$ And JuAn C. Reboreda \\ Departamento de Ecología, Genética y Evolución, Facultad de Ciencias Exactas y Naturales, \\ Universidad de Buenos Aires, Pabellón II Ciudad Universitaria, C1428EHA Buenos Aires, Argentina
}

\begin{abstract}
Brood-parasitic cowbirds (Molothrus spp.) can cause total nest failure directly by inducing nest desertion or by destroying the host's clutch or indirectly by facilitating nest predation. We examined the relationship between brood parasitism and nest survival in the Bay-winged Cowbird (Agelaioides badius), the primary host of the Screaming Cowbird (M. rufoaxillaris) and a secondary host of the Shiny Cowbird (M. bonariensis). We used the program MARK to model daily nest-survival rates, including hypothesized effects of intensity of parasitism, egg losses caused by cowbirds, and total clutch size. Support for each model was evaluated by an informationtheoretic approach. More than $50 \%$ of the nests failed before incubation was completed, mainly because of the ejection or desertion of parasitized clutches. The model of daily nest survival with best support included the additive effects of intensity of parasitism and number of eggs lost, which were negatively related to nest survival. The model including the effect of clutch size did not receive support. The predicted probability of a nest surviving the entire nesting cycle was 35\% for unparasitized nests without egg loss, whereas under the levels of parasitism observed during this study the probability of nest survival varied between 0 and $32 \%$. Nest predation during the egg and nestling stages was positively related to the number of cowbird eggs and chicks, respectively, suggesting that parasitism by Screaming and Shiny Cowbirds may also facilitate depredation of Bay-winged Cowbird nests.
\end{abstract}

Key words: Agelaioides badius, Bay-winged Cowbird, brood parasitism, MARK, Molothrus rufoaxillaris, nest survival, Screaming Cowbird.

\section{El Parasitismo de Cría Aumenta la Mortalidad de Nidos de Agelaioides badius}

Resumen. Los tordos parásitos de cría (Molothrus spp.) pueden causar el fracaso total del nido directamente al inducir el abandono de los nidos o destruir la puesta del hospedador, o indirectamente, a través de facilitar la depredación del nido. Examinamos la relación entre el parasitismo de cría y la supervivencia de nidos en Agelaioides badius, el principal hospedero de $M$. rufoaxillaris y un hospedero secundario de $M$. bonariensis. Usamos el programa MARK para modelar la supervivencia diaria de los nidos incluyendo efectos hipotéticos de la intensidad de parasitismo, la pérdida de huevos causada por los tordos y el tamaño total de la puesta. El respaldo para cada modelo fue evaluado usando una aproximación basada en la teoría de la información. Más del 50\% de los nidos fracasaron antes de completar la incubación, debido principalmente al rechazo o abandono de las puestas parasitadas. El modelo de supervivencia diaria de nidos que tuvo mayor respaldo incluyó el efecto aditivo de la intensidad de parasitismo y el número de huevos picados, que estuvieron relacionados negativamente con la supervivencia del nido. El modelo que incluyó el efecto del tamaño de la puesta no tuvo respaldo. La probabilidad estimada de que un nido sobreviva todo el ciclo de nidificación fue del 35\% para nidos no parasitados sin pérdida de huevos. Sin embargo, bajo los niveles de parasitismo observados durante este estudio, la probabilidad de supervivencia varió entre el 0 y $32 \%$. La depredación de nidos durante las etapas de huevo y pichón estuvo relacionada positivamente con el número de huevos y pichones parásitos, respectivamente, lo que sugiere que el parasitismo de $M$. rufoaxillaris y $M$. bonariensis también podría facilitar la depredación de nidos de $A$. badius.

\section{INTRODUCTION}

Brood-parasitic cowbirds (Molothrus spp.) usually impose severe costs on hosts' reproductive success. Cowbird parasitism often results in the reduction of the host's clutch or brood size as a consequence of the cowbird's removing or puncturing the host's eggs (reviewed by Peer 2006) and higher mortality of the host's chicks due to competition with larger or older cowbird chicks (Payne and Payne 1998, Lorenzana and Sealy 1999, Hoover 2003, Duré Ruiz et al. 2008). Furthermore, the presence of cowbird eggs can reduce the hatching success of the host's eggs as a result of a lower efficiency of incubation or egg-capping (Petit 1991, Peer and Bollinger 1997, Hauber 2003).

Apart from reducing the host's productivity, brood parasitism can cause total nest failure in several ways. In many

${ }^{1}$ E-mail: de_marsico@ege.fcen.uba.ar

The Condor, Vol. 112, Number 2, pages 407-417. ISSN 0010-5422, electronic ISSN 1938-5422. (C) 2010 by The Cooper Ornithological Society. All rights reserved. Please direct all requests for permission to photocopy or reproduce article content through the University of California Press's Rights and Permissions website, http://www.ucpressjournals.com/ reprintInfo.asp. DOI: 10.1525/cond.2010.090118 
host species, egg losses caused by cowbirds and interactions with cowbirds at the nest increase nest-desertion rates (Hill and Sealy 1994, Clotfelter and Yasukawa 1999, Strausberger and Burhans 2001, Kosciuch et al. 2006). Moreover, cowbirds occasionally act as nest predators. For example, the Brownheaded Cowbird (M. ater) may destroy hosts' clutches (Arcese et al. 1996, Hoover and Robinson 2007) and, more rarely, kill the host's chicks (Elliot 1999, Granfors et al. 2001, Smith et al. 2003, Stake and Cimprich 2003).

In addition, brood parasitism and nest predation may have nonadditive effects on the host's survival and fecundity (Grzybowski and Pease 2000). Many authors have suggested that cowbirds may increase nest failure indirectly as they facilitate nest detection by potential predators (Arcese et al. 1992, Massoni and Reboreda 1998, Dearborn 1999, Zanette et al. 2007, Hannon et al. 2009), although others did not find a clear relationship between nest predation and parasitism (e.g., Trine 2000, Hoover 2003, Smith et al. 2003). All these results suggest that, to better understand the consequences of brood parasitism on hosts' productivity, the relative importance of parasitism to nest survival and its possible interactions with nest predation should be considered. However, the effect on hosts' nest survival of parasitic cowbirds other than the Brown-headed remains poorly studied.

Unlike the Brown-headed Cowbird, the Screaming Cowbird (M. rufoaxillaris) is a specialized brood parasite whose primary host is the Bay-winged Cowbird (Agelaioides badius) (Fraga 1998, Ortega 1998). The Bay-winged Cowbird is also a secondary host of the generalist Shiny Cowbird (M. bonariensis; Mason 1980, Fraga 1998), which occurs throughout the Screaming Cowbird's range (Ortega 1998). Nearly all Baywinged Cowbird nests are multiply parasitized (Hoy and Ottow 1964, Mason 1980, Fraga 1998). Indeed, the mean intensity of Screaming Cowbird parasitism of Bay-winged Cowbird nests (three to eight eggs per nest; Fraga 1998 and references therein) is among the highest reported for any cowbird host (Mason 1986, Kattan 1997, Fraga 1998, Trine 2000, Reboreda et al. 2003, Ellison et al. 2006). Fraga (1988) concluded that parasitism by the Screaming Cowbird is the main cause of failure of Bay-winged Cowbird nests. However, because nest predation was unusually rare during his study $(\sim 9 \%$ of the nests; Fraga 1988), it is possible that he overestimated the direct effect of parasitism on nest survival.

Cowbird parasitism can increase the risk of failure of Baywinged Cowbird nests in various ways throughout the nesting cycle, even before hosts begin to lay. Both the Screaming and Shiny Cowbirds often fail to synchronize parasitism of Baywinged Cowbird nests and lay their eggs in advance of the host's laying (Hoy and Ottow 1964, Fraga 1998, De Mársico and Reboreda 2008a). Although Bay-winged Cowbirds usually reject these "premature" parasite eggs, they sometimes desert the nest before laying (Fraga 1988). During the egg stage, multiple parasitism can induce nest failure directly because Bay-winged Cowbirds often evict the entire clutch when the eggs overfill the nest cup (Hoy and Ottow 1964, Fraga 1998). Clutches are usually ejected soon after hosts have completed laying, and ejection is followed by the laying of a replacement clutch in the same nest (Fraga 1998). In addition, both Screaming and Shiny Cowbirds often puncture the host's eggs (Fraga 1998, Llambías et al. 2006), thus multiple visits by the parasites may increase the risk of nest abandonment if they result in more egg losses (Fraga 1998). Parasitism may also affect the Bay-winged Cowbird's nest survival indirectly if the cowbirds' repeated visits attract more predators to the nest. Likewise, during the nestling stage, the presence of the parasite's chicks could facilitate predators' detecting the nest as they beg more intensively than the host's chicks (Lichtenstein 2001). However, whether Screaming and Shiny Cowbird parasitism has indirect effects on the Bay-winged Cowbird's nest survival has not yet been investigated.

The primary aim of this study was to examine how and to what extent cowbird parasitism can affect the Bay-winged Cowbird's nest survival. To disentangle the cues that induce failure of Bay-winged Cowbird nests, we considered three main variables: (1) the number of parasite eggs and chicks present in the nest (intensity of parasitism), (2) the frequency of egg losses due to the parasites puncturing eggs, and (3) the total clutch or brood size (host plus parasite eggs). At the nestling stage, nest predation is the primary cause of nest failure (Fraga 1988), so any effect of parasitism on nest survival at this stage should reflect facilitation of nest predation rather than a direct effect of parasitism. By contrast, at the egg stage parasitism can have both direct and indirect effects. Therefore, to assess the occurrence of indirect effects of parasitism specifically, we modeled nest-survival rates as a function of the intensity of parasitism by using a subset of nests in which incubation was completed or failed because of predation before hatching, thus excluding nests deserted before hatching. Finally, we examined the influence of premature parasitism on early nest desertion, which may imply further costs to the Bay-winged Cowbird of parasitism by the Screaming and Shiny Cowbirds.

\section{METHODS}

\section{STUDY SITE AND DATA COLLECTION}

Our study was conducted at the reserve El Destino, near the town of Magdalena ( $35^{\circ} 08^{\prime} \mathrm{S}, 57^{\circ} 23^{\prime} \mathrm{W}$ ), in the province of Buenos Aires, Argentina. The study site is a flat area of approximately 320 ha within the Biosphere Reserve Parque Costero del Sur (MAB-UNESCO). Vegetation consists of patches of woodland dominated by Celtis tala and Scutia buxifolia, surrounded by grasslands and marshes (Cagnoni et al. 1996). Potential predators of Bay-winged Cowbird nests in the study area are the Chimango Caracara (Milvago chimango), Guira Cuckoo (Guira guira), White-eared Opossum (Didelphis 
albiventris), snakes (e.g., Philodryas spp.), and exotic rodents (e.g., Rattus rattus).

The Bay-winged Cowbird is single brooded (Fraga 1991) and breeds in our study area from late November to late February (De Mársico and Reboreda 2008a). Data were collected over five consecutive breeding seasons from 2002 to 2007. Bay-winged Cowbirds rarely build their own open-cup nests; more often they exploit a wide variety of closed or domed sites, including old nests of many species of the family Furnariidae (e.g., Furnarius rufus, Anumbius annumbi, Synallaxis spp., Phacellodomus spp.), old nests of the Great Kiskadee (Pitangus sulfuratus, Tyrannidae), holes in trees, and nest boxes (Fraga 1988). In 2002, we placed in the study area 50 wooden nest boxes $(30 \times 20 \times 16 \mathrm{~cm}$ with an entrance hole $58 \mathrm{~mm}$ in diameter), attached to trees at a height of $1.80-2.50 \mathrm{~m}$. We partially filled these boxes with artificial nests made of sticks and plant fibers. Another 100 nest boxes, similar yet smaller than those for the Bay-winged Cowbird $(25 \times 17 \times 13$, entrance hole $45 \mathrm{~mm}$, height $1.20-1.80 \mathrm{~m}$ ), were placed in the area for another study of the House Wren (Troglodytes aedon) and have been available to Bay-winged Cowbirds since 2003. Most of them had inactive House Wren nests at the time Bay-winged Cowbirds started breeding.

We searched exhaustively for Bay-winged Cowbird nests from mid November to late January. Nest boxes were checked twice a week to detect any new nesting attempt. We found most nests along the edges of woodland patches or in isolated trees, at heights of $1.30-10 \mathrm{~m}$. About half of the nests found were too high to be accessible to us. Therefore, we limited our study to those nests built at a height of $<5 \mathrm{~m}$, which could be inspected with a portable ladder. We are aware that our sample of all potential nesting sites is thus nonrandom. However, because our primary aim was to assess the effect of brood parasitism on nest mortality and not to estimate actual nestsurvival rates, we are confident that our results are representative of prevalent mechanisms of cowbird-induced nest failure in the population studied.

We monitored a total of 193 Bay-winged Cowbird nests, most found before or during the host's laying $(78 \%)$. Nests were checked every 1-3 days until they failed or fledged chicks. On each visit, we examined nest contents by taking all the eggs or chicks out of the nest. Individual eggs were identified as of the Bay-winged, Screaming, or Shiny Cowbird on the basis of background color, spot pattern, and shape (Friedmann 1929, Fraga 1983, 1986). Nestlings of each species were identified by their diagnostic skin and bill colors (Friedmann 1929, Fraga 1979, 1986). We numbered the eggs and marked the chicks with waterproof ink for identification and inspected each egg for punctures, chicks for lesions. Punctures made by cowbirds are recognizable because they leave a big triangular hole (Astié and Reboreda 2006). We assumed that eggs that disappeared between successive visits were punctured by parasites then removed by hosts as the result of nest sanitation (Astié and Reboreda 2006). To identify fledglings, we banded host and parasite chicks at the age of 10 or 11 days with a unique combination of color leg bands and a numbered aluminum band.

We recorded the fate of each nest as "successful" if we saw at least one host or parasite fledgling out of the nest; "depredated" if nest contents disappeared between successive visits and there was no parental activity near the nest; "deserted" if one or more eggs remained in the nest but were cold to the touch and there was no parental activity near the nest; "ejected" if we found some or all the eggs out of the nest cup but Bay-winged Cowbirds continued to defend the nest, and as "other fate" if the nest failed from accidental or fortuitous causes (e.g., breakage of the supporting branch, flooding, or high ectoparasite load). Screaming and Bay-winged Cowbird young usually remain in the natal territory for at least 3 weeks (Fraga 1986), so we are confident that we correctly distinguished between successful nests and those depredated by the time of fledging. Whenever possible, we assigned to each nest a clutch-initiation date corresponding to the date the host laid its first egg, either directly or through backdating from hatching dates (the Bay-winged Cowbird's incubation period: 13 days from the laying of the penultimate egg; Fraga 1998). In seven nests that were found and failed during incubation, we estimated a mean clutch-initiation date ( $\pm 1-5$ days) by considering the date the nest was found and the last date it was seen active. Because we experimentally added or removed parasite eggs in nearly $39 \%$ of the nests as a part of a larger study (De Mársico and Reboreda 2008b, De Mársico 2009), we categorized each nest as manipulated or not to evaluate whether our manipulations affected nest survival.

\section{STATISTICAL ANALYSES}

Influence of parasitism on nest survival. We used the program MARK 5.1 (White and Burnham 1999) to model daily nestsurvival rates incorporating hypothesized effects of parasitism and evaluated the support for each model by using an information-theoretic approach (Burnham and Anderson 2002). From the original data set, we excluded 20 nests for which data were insufficient for nest-survival analysis, 9 that failed from accidental causes, and 11 where the hosts never laid eggs. Therefore, the sample consisted of 153 nests (10 in 2002, 23 in 2003, 31 in 2004, 31 in 2005, and 58 in 2006). To estimate the effect of parasitism on daily survival rates at various stages of the nesting cycle, we divided the data set into three groups corresponding to the laying, incubation, and nestling stages. For nests belonging to more than one group, we truncated the observation period on the last day of the first stage (see below), then initiated it on that day for the following stage (Dinsmore and Dinsmore 2007). For nests that successfully completed each stage, the observation period was truncated on the date of clutch completion (laying stage), the date of hatching of the host's first chick (incubation stage), and the 
date of departure of the fledglings (nestling stage). When the exact date of fledging was unknown, the observation period was truncated at the average age of fledging (14 days for Baywinged Cowbird and parasite chicks, range 12-16 days; Fraga 1998; MCDM and JCR, unpubl. data). All dates were scaled so that day 1 was the clutch-initiation date of the earliest nest in our sample (27 November). An assumption of the nestsurvival model in MARK is that nest fates are independent (Dinsmore et al. 2002). We assumed this for successive nesting attempts in the same site (i.e., renesting after removal of the entire clutch) on the basis that the survival of nests found before or during the host's laying was not associated with the order of the nesting attempt (11 of 88, 7 of 30, and 3 of 10 successful nests among first, second, and third nesting attempts; chi-squared test: $\chi_{2}^{2}=3.38, P=0.18$ ).

We analyzed the effect on daily survival rate of intensity of parasitism, frequency of egg losses caused by parasites, and clutch size. The intensity of parasitism was measured in two ways: (1) total intensity, defined as the cumulative number of parasite eggs laid during or after the host's laying (laying and incubation stages) or parasite chicks hatched per nest (nestling stage), and (2) effective intensity, defined as the cumulative number of parasite eggs laid (laying and incubation stages) or parasite chicks hatched (nestling stage) synchronously with the host's eggs or chicks. We used these covariates to account for the effect on nest survival of frequency of parasitism over the nesting cycle and timing of parasitism. We did not analyze the effect of parasitism of each species separately because the intensity of Screaming Cowbird parasitism was strongly correlated with the total intensity of parasitism $\left(r^{2}=0.97\right)$ and Shiny Cowbird parasitism was too infrequent to yield meaningful estimates of its effect on nest survival. The frequency of egg losses was measured as the total number of eggs (host plus parasite) that were punctured or missing, which reflect both losses of the host's eggs and general disturbance caused by punctures. Bay-winged Cowbirds do not discriminate among eggs (Mason 1980, Fraga 1998; MCDM and JCR, unpubl. data), so we assumed that hosts do not respond differently toward punctures inflicted on their own or parasitic eggs. We defined clutch and brood sizes, respectively, as the number of eggs remaining at the end of the laying stage and the number of host and parasite chicks that hatched synchronously (including the eggs or chicks experimentally added to the nest).

The incidence of cowbird parasitism may vary through the breeding season and by year. In addition, the risk of parasite-induced mortality could differ by nesting site if some types of nests are more vulnerable to parasitism than others. Hence, we began by fitting a set of exploratory models to examine the effect on daily survival rate of year, time of the breeding season across and within stage of nesting (following linear and quadratic trends), stage of nesting, nest type, and experimental manipulation within stage of nesting. We categorized nest types as "furnariid-like" (closed nests made of sticks or mud), "cavities" (nest boxes and holes in trees), or "other" (open cups and domed nests made of grass). We also fitted a model assuming a daily survival rate constant over time and across nesting sites (hereafter the constant model, which included only an intercept). We then fitted models that singly included each parasitism-related covariate and, finally, an additive model combining the best-performing covariate of the intensity of parasitism or clutch size with the frequency of egg losses.

To assess indirect effects of parasitism at the egg stage, we modeled the daily survival rate for a subset of nests in which incubation was completed or that were depredated before hatching $(n=80)$. For successful nests, we truncated the observation period on the date the first host chick hatched. Again, we began by fitting exploratory models that allow daily survival rate to vary with year, nest type, time of breeding (with linear and quadratic trends), and the constant model including only the intercept. We then fitted a model including the total intensity of parasitism and additive models combining the intensity of parasitism with seasonal trends.

All models were built without standardizing covariates and with the sine (for constant models) or logit-link function (for models including covariates; Dinsmore et al. 2002). We used Akaike's information criterion corrected for small sample sizes $\left(\mathrm{AIC}_{c}\right)$ and the associated Akaike weights $\left(w_{i}\right)$ to evaluate support for competing models within the set of candidate models (Burnham and Anderson 2002). We considered that models with $\mathrm{AIC}_{c}$ differing by $\leq 2.00$ units were equally supported by the data (Burnham and Anderson 2002). When the top model was strongly supported $\left(w_{i} \geq 0.90\right)$, we report parameter estimates from this single best model (Burnham and Anderson 2002). When no model was clearly the best, we identified a $90 \%$ confidence set and report results from the competing models within that set to account for uncertainty of model selection (Burnham and Anderson 2002). We did not use model averaging because our models reflect different hypothesized relationships between the covariates of interest and daily survival rate (e.g., linear and quadratic time trends in nest survival). Daily survival estimates were obtained from the logistic-regression equation of the best-supported model. For each stage of nesting, survival probabilities were the product of daily survival rate over the assumed duration of each stage (4 days of laying, 12 of incubation, and 14 of nestling for a nest with the modal clutch size of four Bay-winged Cowbird eggs). We then calculated the predicted probability of a nest surviving the entire cycle by multiplying the survival probabilities of the three stages.

Influence of parasitism on early nest desertion. To analyze the relationship between early nest desertion and premature parasitism, we fitted a generalized linear model with a binomial error distribution and the logit-link function with the host's response (laying/desertion) as the binary dependent 
variable. The explanatory variables were (1) number of parasite eggs laid before the host's laying and (2) occurrence of punctures of parasitic eggs before the host began laying (binary variable). The sample consisted of 34 nests parasitized at least once before the host began laying. We considered only the first nest attempted in each nest site.

We fitted the generalized linear model by using R 2.9.0 (R Development Core Team 2008). Other statistical tests were done with StatView 5.0 (SAS Institute 1998). In the Results, values are presented as mean \pm SE. All tests were two-tailed, and significance was accepted at $P<0.05$.

\section{RESULTS}

\section{SOURCES OF NEST MORTALITY AND}

\section{INCIDENCE OF COWBIRD PARASITISM}

We monitored 153 Bay-winged Cowbird nests over a 91-day interval (from 27 November to 26 February) for a total of 1831 exposure days (Fig. 1). Most nests were found in old closed furnariid nests $(n=89)$ and nest boxes $(n=36)$. Other nest sites were domed Great Kiskadee nests $(n=12)$, natural cavities $(n=10)$, open-cup nests built by Bay-winged Cowbirds $(n=5)$, and a broken nest of the paper wasp Polybia scutellaris. Thirty-four of these nests (22\%) produced fledglings, 53 $(35 \%)$ were depredated during the egg (31 nests) or nestling (22 nests) stages, 28 (18\%) were deserted before hatching, and $38(25 \%)$ failed because of clutch ejection.

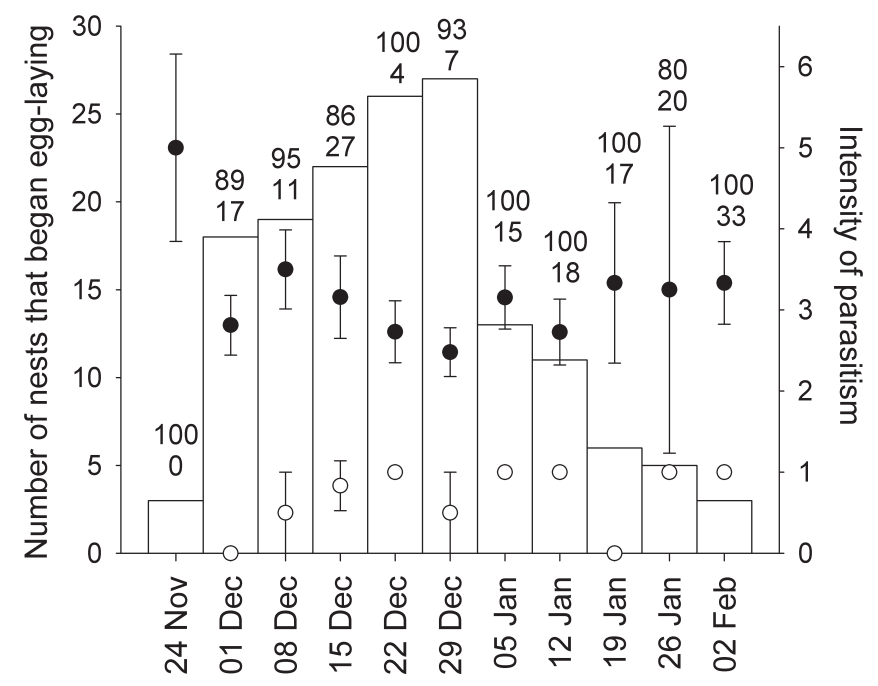

FIGURE 1. Seasonal distribution and incidence of parasitism in Bay-winged Cowbird nests at Reserve El Destino, Buenos Aires, 2002-2007. The bars represent the number of Bay-winged Cowbird clutches initiated each week. By week, the symbols represent the number of Screaming and Shiny Cowbird eggs laid per parasitized nest after the hosts began laying (mean $\pm \mathrm{SE}$ ). Numbers above bars indicate the proportion of nests parasitized by Screaming (upper) and Shiny (lower) Cowbirds each week.
Nine nests (6\%) were unparasitized, $123(80 \%)$ were parasitized by Screaming Cowbirds, and $21(14 \%)$ were parasitized by both Screaming and Shiny Cowbirds. Average size of Baywinged Cowbird clutches was $3.8 \pm 0.1$ eggs (range $2-5 ; n=81$ nests found before the onset of incubation and that survived until clutch completion). Average intensities of parasitism over the entire nesting cycle (considering parasitized nests found before or during the host's laying) were $5.1 \pm 0.3$ Screaming Cowbird eggs (range $1-18, n=120$ nests) and $1.4 \pm 0.1$ Shiny Cowbird eggs (range 1-2, $n=18$ nests) per nest. When we excluded cowbird eggs laid before the host laid, the corresponding intensities were $3.5 \pm 0.2$ (range $0-9$ ) and $0.5 \pm 0.2$ (range $0-2$ ) eggs per nest (Fig. 1). Among nests that survived until the nestling stage $(n=56), 13$ were not parasitized. The other 43 nests had only Screaming Cowbird $(n=23)$, only Shiny Cowbird $(n=9)$, or Screaming and Shiny Cowbird $(n=11)$ chicks. Twenty of these nests had been artificially parasitized with one Shiny Cowbird egg $(n=14)$ or a newly hatched chick $(n=6)$. The intensity of parasitism at the nestling stage was $1.7 \pm 0.2$ Screaming Cowbird (range 1-5, $n=34$ nests) and 1.0 Shiny Cowbird $(n=20)$ chicks per nest.

In 36 of 153 nests, Bay-winged Cowbirds ejected the entire clutch and attempted a second nest in the same site. Twentyfive of $33(76 \%)$ nests with ejected clutches were also parasitized during the second attempt. However, these nests received fewer parasitic eggs in the second than in the first attempt (2.1 \pm 0.3 vs. $3.6 \pm 0.3$ eggs; Wilcoxon signed-rank test: $z=-3.62$, $P<0.001, n=25$ nests). In ten of 25 cases, Bay-winged Cowbirds also ejected the second clutch and laid a third one. Seven of these nests were again parasitized during the third attempt, but the intensity of parasitism of second and third clutches did not differ ( $2.3 \pm 0.8$ vs. $2.0 \pm 0.5$ parasite eggs per nest; Wilcoxon signed-rank test: $z=-0.65, P=0.52, n=7)$. Mean dates of initiation of first, second, and third nesting clutches were 21 December, 2 January, and 9 January, respectively.

\section{INFLUENCE OF PARASITISM ON NEST SURVIVAL}

Daily nest survival was related to the intensity of parasitism and frequency of egg losses due to parasites (Tables 1 and 2). The data strongly supported the model containing the additive effects of effective intensity of parasitism and number of eggs punctured $\left(w_{i}=0.98\right)$. In contrast, models including the effect of total clutch size on daily nest survival did not receive support $\left(\Delta \mathrm{AIC}_{c}>24.7, w_{i}=0.00\right)$. Likewise, there was little evidence for an effect on nest survival of nesting stage, year, nest type, experimental manipulation, or linear or quadratic seasonal trend $\left(\Delta \mathrm{AIC}_{c}>29.1, w_{i}=0.00\right)$. Parameter estimates of the top model indicated that at each stage of nesting daily nest survival decreased linearly with number of synchronous cowbird eggs or chicks (Table 2). For the incubation and nestling stages, however, $95 \%$ confidence intervals for parameter estimates included zero (Table 2). In addition, daily nest survival during laying and incubation decreased with number of 
TABLE 1. Support for models predicting survival of Bay-winged Cowbird nests at Reserve El Destino, Buenos Aires (2002-2007). Deviance $=$ difference between each model and the saturated model in $-2 \log$ likelihood; $\Delta \mathrm{AIC}_{c}=$ difference between each model and the top model in Akaike's information criterion corrected for small samples $\left(\mathrm{AIC}_{c}\right) ; K=$ number of parameters in the model; $w_{i}=$ Akaike weight, a measure of each model's relative support within the set of candidate models. See Methods for definition of model covariates.

\begin{tabular}{lcccc}
\hline \hline Model & Deviance & $\Delta \mathrm{AIC}_{c}$ & $K$ & $w_{i}$ \\
\hline $\begin{array}{c}\text { Effective intensity of } \\
\text { parasitism + egg } \\
\text { punctures by nest } \\
\quad \text { stage }\end{array}$ & 668.67 & 0.00 & 8 & 0.98 \\
$\begin{array}{c}\text { Egg punctures (laying and } \\
\text { incubation stages only) }\end{array}$ & 683.81 & 9.08 & 5 & 0.01 \\
$\begin{array}{c}\text { Effective intensity of } \\
\text { parasitism by nest stage }\end{array}$ & 682.65 & 9.95 & 6 & 0.01 \\
$\begin{array}{c}\text { Total intensity of } \\
\text { parasitism by nest stage }\end{array}$ & 686.01 & 13.30 & 6 & 0.00 \\
\begin{tabular}{c} 
Clutch size by nest stage \\
\hline
\end{tabular} & 693.36 & 24.68 & 8 & 0.00 \\
\hline
\end{tabular}

${ }^{\mathrm{a} A I C}{ }_{c}$ value of the top model $=684.76$.

punctured eggs, but parameter estimates suggest that this effect was greater during incubation (Table 2, Fig. 2).

Observed daily survival rates for unparasitized nests with the modal clutch size were $0.932,0.965$ and 0.974 for the laying, incubation and nestling stages, respectively, yielding predicted probabilities of surviving each stage of $0.76,0.67$,

TABLE 2. Parameter estimates, standard errors, and 95\% confidence intervals for the top logistic-regression models explaining survival of Bay-winged Cowbird nests at Reserve El Destino, Buenos Aires (2002-2007).

\begin{tabular}{|c|c|c|c|c|}
\hline \multirow[b]{2}{*}{ Parameter } & \multirow[b]{2}{*}{ Estimate } & \multirow[b]{2}{*}{ SE } & \multicolumn{2}{|c|}{$\begin{array}{l}\text { Confidence } \\
\text { interval }\end{array}$} \\
\hline & & & Lower & Upper \\
\hline Intercept (laying) & 2.62 & 0.28 & 2.07 & 3.18 \\
\hline $\begin{array}{l}\text { Intercept } \\
\quad \text { (incubation) }\end{array}$ & 3.39 & 0.23 & 2.93 & 3.85 \\
\hline Intercept (nestling) & 3.61 & 0.35 & 2.92 & 4.30 \\
\hline $\begin{array}{l}\text { Effective intensity } \\
\text { of parasitism } \\
\text { (laying) }\end{array}$ & -0.25 & 0.08 & -0.40 & -0.10 \\
\hline $\begin{array}{l}\text { Effective intensity } \\
\text { of parasitism } \\
\text { (incubation) }\end{array}$ & -0.19 & 0.10 & -0.39 & 0.01 \\
\hline $\begin{array}{l}\text { Effective intensity } \\
\text { of parasitism } \\
\text { (nestling) }\end{array}$ & -0.26 & 0.21 & -0.66 & 0.15 \\
\hline $\begin{array}{l}\text { Number of egg } \\
\text { punctures (laying) }\end{array}$ & -0.13 & 0.12 & -0.37 & 0.10 \\
\hline $\begin{array}{l}\text { Number of } \\
\text { egg punctures } \\
\text { (incubation) }\end{array}$ & -0.46 & 0.12 & -0.70 & -0.22 \\
\hline
\end{tabular}
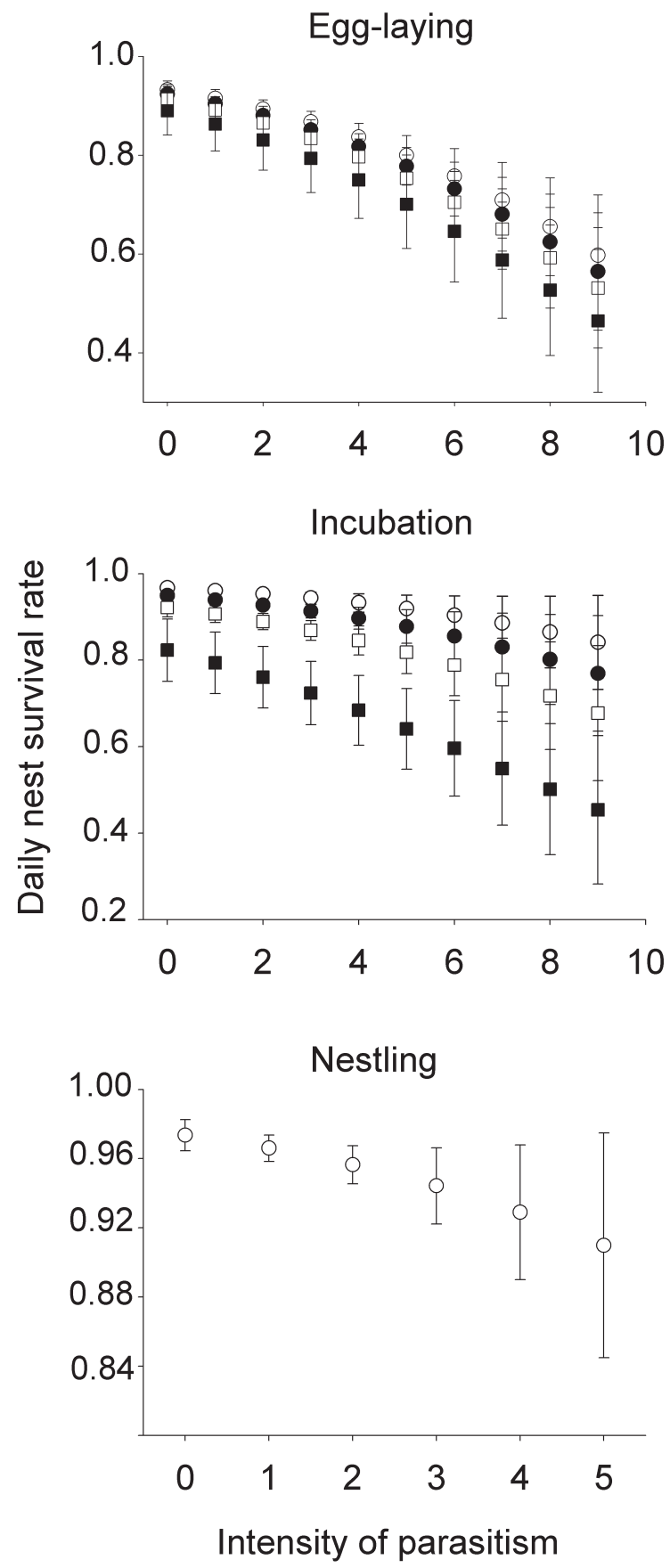

FIGURE 2. Predicted daily survival rates of Bay-winged Cowbird nests at the laying, incubation, and nestling stages in relation to effective intensity of parasitism and number of eggs punctured (laying and incubation stages). Effective intensity of parasitism refers to the number of cowbird eggs laid while the host was laying or the number of cowbird chicks of an age similar to that of the host's chicks. Estimates were generated from the logistic-regression equation of the top model (Tables 1 and 2) for intensities of parasitism and frequencies of egg losses within the range observed during this study. The symbols represent the estimated daily survival rate with the corresponding standard errors. For the laying and incubation stages, different curves illustrate the predicted daily survival rate for nests having $0(0), 1(\bullet), 2(\square)$, or $4(\square)$ punctured eggs. 
TABLE 3. Support for models predicting daily survival rates at the egg stage for Bay-winged Cowbird nests at Reserve El Destino, Buenos Aires (2002-2007). Only nests that completed incubation or were depredated before hatching were included in the analysis. Deviance $=$ difference between each model and the saturated model in $-2 \log$ likelihood; $\Delta \mathrm{AIC}_{c}=$ difference between each model and the top model in Akaike's information criterion corrected for small samples $\left(\mathrm{AIC}_{c}\right) ; K=$ number of parameters in the model; $w_{i}=$ Akaike weight, a measure of each model's relative support within the set of candidate models. See Methods for definition of model covariates.

\begin{tabular}{lcccc}
\hline \hline Model & Deviance & $\Delta \mathrm{AIC}_{c}$ & $K$ & $w_{i}$ \\
\hline $\begin{array}{l}\text { Seasonal trend (quadratic) }+ \\
\quad \text { intensity of parasitism }\end{array}$ & 184.77 & 0.00 & 4 & 0.68 \\
$\begin{array}{l}\text { Seasonal trend (quadratic) } \\
\text { Seasonal trend (linear) }+\end{array}$ & 188.95 & 2.16 & 3 & 0.23 \\
$\quad$ intensity of parasitism & 192.14 & 5.35 & 3 & 0.05 \\
$\quad$ Seasonal trend (linear) & 195.20 & 6.39 & 2 & 0.03 \\
Intensity of parasitism & 198.91 & 10.11 & 2 & 0.00 \\
\hline
\end{tabular}

${ }^{\mathrm{a} A I C}{ }_{c}$ value of the top model $=192.82$.

and 0.69. When the effective intensities of the parasitism we observed (one to nine parasite eggs and one to five parasite chicks per nest) are taken in to account, daily survival rates of Bay-winged Cowbird nests dropped from 0.915 to 0.608 , 0.965 to 0.868 , and 0.974 to 0.910 for the laying, incubation, and nestling stages, respectively. Accordingly, probabilities of surviving each stage ranged from 0.70 to $0.05,0.62$ to 0 , and 0.62 to 0.27 for the laying, incubation, and nestling stages, respectively. The predicted probability of surviving the entire nesting cycle was 0.35 for unparasitized nests in which no eggs were punctured and varied from zero to 0.32 for parasitized nests.

Models of daily survival rate for nests that completed incubation or were depredated before hatching ( $n=80$ nests, 863 observation days between 27 November and 14 February) provided some evidence for a relationship between parasitism and nest predation at the egg stage. The model that singly included intensity of parasitism performed poorly $\left(\triangle \mathrm{AIC}_{c}=\right.$ $10.1, w_{i}=0.00$ ) but there was support for an additive effect of the number of cowbird eggs laid and a quadratic seasonal trend $\left(w_{i}=0.68\right.$; Table 3). Parameter estimates for the $90 \%$ confidence set of models showed a weak trend toward lower nest survival in the middle of the breeding season and a negative effect of intensity of parasitism on nest survival (Table 4). Models including the effect of year, nest type, and experimental manipulation received little support $\left(\Delta \mathrm{AIC}_{c}>11.9\right.$, $w_{i}<0.00$; Table 3).

\section{INFLUENCE OF PARASITISM ON \\ EARLY NEST ABANDONMENT}

Bay-winged Cowbirds deserted 11 nests before laying. These nests received $4.5 \pm 0.8$ parasitic eggs (range $1-10, n=11$ ), whereas nests in which the host laid received $1.8 \pm 0.4$ parasitic eggs before the host began laying (range: $0-9, n=41$ nests; Mann-Whitney $U$-test: $U=85.5, P=0.004)$. When only the nests that were parasitized before the host's laying are considered $(n=34)$, early desertion was unrelated to the intensity of "premature" parasitism (general linear model: coefficient $\pm \mathrm{SE}=0.06 \pm 0.15$, Wald $\chi^{2}=0.14, P=0.71$ ), but it was positively related to the puncturing of eggs prior to the host's laying (coefficient $\pm \mathrm{SE}=1.90 \pm 0.89$, Wald $\chi_{1}^{2}=4.59$, $P=0.03$ ).

\section{DISCUSSION}

Our results show that cowbird parasitism affects survival of Bay-winged Cowbird nests greatly. The apparent survival rates indicate that clutch ejection was the most common source of nest mortality during the egg stage. Taken together, clutch ejection and nest desertion accounted for more nest failures over the nesting cycle than did predation on eggs and chicks. However, predation was responsible for more nest failures than was either clutch ejection or nest desertion alone, and predation was the main cause of nest failure during the nestling stage. Hence, both cowbird parasitism and predation

TABLE 4. Parameter estimates, standard errors, and $95 \%$ confidence intervals for the $90 \%$ confidence set of logistic-regression models explaining survival at the egg stage of Bay-winged Cowbird nests at Reserve El Destino, Buenos Aires (2002-2007). Models were built only on the basis of nests in which incubation was completed or that were depredated before hatching. See Methods for definition of model covariates.

\begin{tabular}{|c|c|c|c|c|c|}
\hline \multirow[b]{2}{*}{ Model } & \multirow[b]{2}{*}{ Parameter } & \multirow[b]{2}{*}{ Estimate } & \multirow[b]{2}{*}{ SE } & \multicolumn{2}{|c|}{ Confidence interval } \\
\hline & & & & Lower & Upper \\
\hline \multirow{4}{*}{$\begin{array}{l}\text { Seasonal trend (quadratic) + } \\
\text { intensity of parasitism }\end{array}$} & Intercept & 3.29 & 0.89 & 1.54 & 5.03 \\
\hline & Time & 0.09 & 0.04 & 0.00 & 0.17 \\
\hline & Time $^{2}$ & -0.001 & 0.000 & -0.002 & 0.000 \\
\hline & Intensity of parasitism & -0.21 & 0.10 & -0.41 & -0.02 \\
\hline \multirow[t]{3}{*}{ Seasonal trend (quadratic) } & Intercept & 2.62 & 0.83 & 1.00 & 4.24 \\
\hline & Time & 0.08 & 0.04 & 0.00 & 0.17 \\
\hline & Time $^{2}$ & -0.0013 & 0.0005 & -0.0023 & -0.0004 \\
\hline
\end{tabular}


determined the survival of the nests we studied. These results partially disagree with those of Fraga (1988), who suggested a minor role of predation in explaining failure of Bay-winged Cowbird nests. This discrepancy cannot be attributed to nest sampling (i.e., nests at heights lower than $10 \mathrm{~m}$ ) as Fraga's estimations were also based on accessible nests found before or during the host's egg laying (Fraga 1988). Potential explanations for the discrepancy between our results and those of Fraga (1998) could be differences in habitat structure, nest location, or predator abundance.

We found that daily nest-survival rate was negatively related to intensity of parasitism and number of eggs punctured. Interestingly, this pattern was better explained by intensity of synchronous parasitism than by total number of cowbird eggs laid, indicating that both intensity and timing of parasitism contributed to nest failures. This result is expected, as synchronous parasitism is the most detrimental to the host's reproductive success, and therefore hosts may benefit from ejecting clutches or deserting nests parasitized before the onset of incubation (Goguen and Matthews 1996, Budnik et al. 2001). Whether nest desertion is an antiparasitic defense (Graham 1988, Hosoi and Rothstein 2000) or a generalized response to partial or total loss of a clutch (Hill and Sealy 1994, Kosciuch et al. 2006) has been a matter of debate. In the Baywinged Cowbird, nest desertion appears to be a nonspecific response to massive or repeated egg losses caused by parasites or predators, and it could be costly for hosts if the opportunities of finding a new nest are limited (Petit 1991). In contrast, clutch ejection seems to be a specific response to multiple parasitism that allows Bay-winged Cowbirds to avoid investing in heavily parasitized clutches without paying the costs of finding or building a new nest (Hauber 2002). Theoretical and empirical studies suggest that the benefits of deserting a parasitized nest might vary within and across breeding seasons according to the costs of parasitism to the host's productivity and the chances of escaping parasitism and nest predation in future nesting attempts (Goguen and Mathews 1996, Budnik et al. 2001, Grzybowski and Pease 2000, Hoover et al. 2006). Our results indicate that clutch ejection did not help Bay-winged Cowbirds to escape brood parasitism, as most replacement clutches were also parasitized by Screaming Cowbirds. However, second Bay-winged Cowbird nests received fewer parasitic eggs than did first nests, suggesting that clutch ejection may benefit hosts through a lower intensity of parasitism. Therefore, clutch ejection could be considered a true antiparasitic defense, as it reduces the effect of multiple parasitism and appears to have evolved in response to selection pressures arising from parasitism (Rothstein 1990).

We did not detect an effect of clutch size on daily nestsurvival rates. This result was unexpected because previous studies indicated that Bay-winged Cowbirds usually eject or desert reduced or enlarged clutches (Hoy and Ottow 1964, Fraga 1998). Clutch reduction below an acceptance threshold has been identified as a cue eliciting nest desertion by other cowbird hosts (Rothstein 1982, Sealy 1992, Mermoz and Reboreda 1998, Kosciuch et al. 2006). A possible explanation for these results is that Bay-winged Cowbirds do not respond to clutch volume or surface area per se but to interactions with parasitic cowbirds at the nest, which were better reflected by intensity of parasitism. In support of this idea, studies of other host-parasite systems indicate that the presence of the parasite near the nest may be important in eliciting nest desertion or egg rejection (Davies and Brooke 1988, Moksnes and Røskaft 1989, Strausberger and Burhans 2001). The fact that survival of its nests was unrelated to experimental manipulations involving addition or removal of parasitic eggs provides further evidence that the Bay-winged Cowbird does not simply desert or eject clutches in response to changes in clutch size. Moreover, because partial reduction of Bay-winged Cowbird clutches is typically the result of egg breakage rather than egg removal, hosts might be more sensitive to disturbances at the nest rather than to changes in clutch size alone. In support of this interpretation, egg puncturing has been reported to trigger nest desertion by various hosts of the Shiny Cowbird that do not abandon nests in response to parasitism (Mermoz and Reboreda 1998, Massoni and Reboreda 2002, Astié and Reboreda 2006).

It has been suggested that clutch destruction by female parasitic cowbirds could be a strategy to force hosts to renest when the nests are found too late for successful parasitism (Arcese et al. 1992, 1996). In some cases, we observed Baywinged Cowbirds abandoning nest after massive puncturing of eggs during early incubation, which suggests that Screaming or Shiny Cowbirds may occasionally use egg puncturing to generate new opportunities for parasitism. For the Brownheaded Cowbird, there is evidence of females attacking host chicks or pulling them out of the nest (Granfors et al. 2001, Smith et al. 2003). To our knowledge, similar behavior by the Screaming or Shiny Cowbirds has not been documented. During this study, we recorded a single case of a seven-day old Bay-winged Cowbird chick injured in an unparasitized nest. However, because this nest was found empty the following day, it seems more likely that a true nest predator rather than a parasitic cowbird was responsible for the attack.

Cowbird parasitism was also involved in Bay-winged Cowbirds deserting nest sites before they began laying, although we noted this response relatively rarely. Nests deserted early received more parasitic eggs than did those in which Bay-winged Cowbirds laid eggs, and the probability of desertion before laying was strongly related to the occurrence of punctured eggs before the host's laying. Because Bay-winged Cowbirds typically reject parasite eggs laid prematurely (Hoy and Ottow 1964, Fraga 1998) and punctures at the prelaying stage damage only parasite eggs, it is not clear why hosts abandoned the nests without laying. A plausible explanation is that desertion is a generalized response to harassment 
from cowbirds and major disturbances at early stages of the nesting cycle.

In addition to the direct effects on nest survival, cowbird parasitism might facilitate nest predation by increasing the risk of predators detecting the nest (Arcese et al. 1992, Massoni and Reboreda 1998, Dearborn 1999, Zanette et al. 2007). Our results suggest that this is possible for Screaming and Shiny Cowbirds parasitizing the Bay-winged Cowbird, as the probability of nest predation was positively related to the number of parasitic eggs and chicks. The positive relationship between parasitism and nest predation at the egg stage suggests that repeated visits by the parasites could contribute to making the nest more conspicuous to potential predators. Other factors not included in our models, such as microhabitat characteristics or parental activity (Martin 1993, Cresswell 1997, Martin et al. 2000, Tewksbury et al. 2002), may also have influenced the pattern of nest survival. Therefore, further experimental work is needed to assess the influence of Screaming and Shiny Cowbird parasitism on nest predation.

Finally, it is worth noting that cowbird-induced nest failures can be costly for the parasites too. Kosciuch and Sandercock (2008) showed that Bell's Vireo (Vireo bellii) nests produced more cowbird fledglings in plots where female Brown-headed Cowbirds were experimentally removed. This was because in plots where cowbirds were removed fewer nests were deserted because of egg losses caused by cowbirds, which resulted in parasitized nests surviving at a higher rate than in unmanipulated plots (Kosciuch and Sandercock 2008). In our study, $44 \%$ of the Screaming Cowbird eggs found ( $n=415$ eggs in 153 nests) were lost in ejected and deserted clutches, which suggests that multiple parasitism of Bay-winged Cowbird nests was costly for parasites, too. Future studies should investigate whether egg-laying behavior, fecundity, and investment in egg content of individual female Screaming Cowbirds reflect the trade-off between specialization in host use and intraspecific competition.

In summary, our data indicate that both cowbird parasitism and nest predation were determinants of the Bay-winged Cowbird's nest survival. Parasitism had strong direct effects on nest survival at the egg stage by increasing the probability of nest abandonment and clutch ejection, whereas predation was the primary cause of nest failure at the nestling stage. In addition, our results provide the first evidence for a positive relationship between parasitism and predation of Bay-winged Cowbird nests, which suggests that parasitism by the Screaming Cowbird could also have indirect effects on the host's nest survival.

\section{ACKNOWLEDGMENTS}

We thank Fundación Elsa Shaw de Pearson for allowing us to conduct this study at the Reserve El Destino. We are also grateful to Gustavo J. Fernández and Bettina Mahler for their helpful suggestions on earlier versions of the manuscript. MCDM was supported by a fellowship from the Consejo Nacional de Investigaciones Científicas y Técnicas (CONICET). JCR is a research fellow of CONICET. This work was supported by the Agencia Nacional de Promoción Científica y Tecnológica (grant 06-00215), University of Buenos Aires (grant X184), and the Student Grant Program of the Neotropical Grassland Conservancy.

\section{LITERATURE CITED}

Arcese, P., J. N. M. Smith, W. M. HochachKa, C. M. Rogers, AND D. LudwIG. 1992. Stability, regulation, and the determination of abundance in an insular Song Sparrow population. Ecology 73:805-822.

Arcese, P., J. N. M. Smith, And M. I. Hatch. 1996. Nest predation by cowbirds and its consequences for passerine demography. Proceedings of the National Academy of Sciences USA 93:4608-4611.

Astié, A. A., AND J. C. ReboredA. 2006. Costs of egg punctures and parasitism by Shiny Cowbirds (Molothrus bonariensis) at Creamy-bellied Thrush (Turdus amaurochalinus) nests. Auk 123:23-32.

Budnik, J. M., D. E. Burhans, M. R. Ryan, and F. R. Thompson. 2001. Nest desertion and apparent nest protection behavior by Bell's Vireos in response to cowbird parasitism. Condor 103:639643.

Burnham, K. P., And D. R. Anderson. 2002. Model selection and multimodel inference, 2nd ed. Springer-Verlag, New York.

Cagnoni, M., A. M. Faggi, AND A. Ribichich. 1996. La vegetación de la Reserva "El Destino" (Partido de Magdalena, Provincia de Buenos Aires). Parodiana 9:25-44.

Clotfelter, E. D., And K. Yasukawa. 1999. Impact of brood parasitism by Brown-headed Cowbirds on Red-winged Blackbird reproductive success. Condor 101:105-114.

Cresswell, W. 1997. Nest predation: the relative effects of nest characteristics, clutch size and parental behaviour. Animal Behaviour 53:93-103.

Davies, N. B., AND M. DE L. BRooke. 1988. Cuckoos versus Reed Warblers: adaptations and counteradaptations. Animal Behaviour 36:262-284.

DEARBorn, D. C. 1999. Brown-headed Cowbird nestling vocalizations and risk of nest predation. Auk 116:448-457.

De MÁrsico, M. C. 2009. Estrategias de uso de hospedadores en el Tordo Pico Corto (Molothrus rufoaxillaris) y el Tordo Renegrido (M. bonariensis), e interacciones con un hospedador compartido, el Músico (Agelaioides badius). Ph.D. dissertation, University of Buenos Aires, Argentina.

De MÁrsico, M. C., AND J. C. ReboredA. 2008a. Egg-laying behavior in Screaming Cowbirds: why does a specialist brood parasite waste so many eggs? Condor 110:143-153.

De MÁrsico, M. C., AND J. C. ReboredA. 2008b. Differential reproductive success favours strong host preference in a highly specialized brood parasite. Proceedings of the Royal Society B 275: 2499-2506.

Dinsmore, S. J., G. C. White, And F. L. Knopf. 2002. Advanced techniques for modeling nest survival. Ecology 94:3476-3488.

Dinsmore, S. J., And J. J. Dinsmore. 2007. Modeling avian nest survival in program MARK. Studies in Avian Biology 34: $73-83$.

Duré Ruiz, N. M., M. E. Mermoz, and G. J. Fernández. 2008. Effect of cowbird parasitism on brood reduction in the Brownand-yellow Marshbird. Condor 110:507-513.

ElLIOT, P. F. 1999. Killing of host nestlings by the Brown-headed Cowbird. Journal of Field Ornithology 70:55-57. 
Ellison, K., S. G. Sealy, and H. L. GibBs. 2006. Genetic elucidation of host use by individual sympatric Bronzed Cowbirds (M. aeneus) and Brown-headed Cowbirds (M. ater). Canadian Journal of Zoology 84:1269-1280.

FraGA, R. M. 1979. Differences between nestlings and fledglings of Screaming and Bay-winged Cowbirds. Wilson Bulletin 91: 151-154.

FragA, R. M. 1983. The eggs of the parasitic Screaming Cowbird (Molothrus rufoaxillaris) and its host, the Bay-winged Cowbird (M. badius): is there evidence for mimicry? Journal für Ornithologie 124:187-193.

Fraga, R. M. 1986. The Bay-winged Cowbird (Molothrus badius) and its brood parasites: interactions, coevolution and comparative efficiency. Ph.D. dissertation, University of California, Santa Barbara, CA.

FraGA, R. M. 1988. Nest sites and breeding success of Bay-winged Cowbirds (Molothrus badius). Journal für Ornithologie 129:175183.

FraGA, R. M. 1991. The social system of a communal breeder, the Bay-winged Cowbird Molothrus badius. Ethology 89:125-210.

FrAGA, R. M. 1998. Interactions of the parasitic Screaming and Shiny Cowbirds (Molothrus rufoaxillaris and M. bonariensis) with a shared host, the Bay-winged Cowbird (Molothrus badius), p. 173-193. In S. I. Rothstein and S. K. Robinson [EDS.], Parasitic cowbirds and their hosts. Studies in coevolution. Oxford University Press, New York.

Friedmann, H. 1929. The cowbirds. A study in the biology of social parasitism. C. C. Thomas, Springfield, IL.

Goguen, C. B., And N. E. Mathews. 1996. Nest desertion by Bluegray Gnatcatchers in association with Brown-headed Cowbird parasitism. Animal Behaviour 52:613-619.

Graham, D. S. 1988. Responses of five host species to cowbird parasitism. Condor 90:588-591.

Granfors, D. A., P. J. Pietz, And L. A. Joyal. 2001. Frequency of egg and nestling destruction by female Brown-headed Cowbirds at grassland nests. Auk 118:765-769.

Grzybowski, J. A., AND C. M. PEASE. 2000. Comparing the relative effects of brood parasitism and nest predation on seasonal fecundity in passerine birds, p. 145-155. In J. N. M. Smith, T. L. Cook, S. I. Rothstein, S. K. Robinson, and S. G. Sealy [EDS.], Ecology and management of cowbirds and their hosts. University of Texas Press, Austin, TX.

Hannon, S. J., S. Wilson, and C. A. McCallum. 2009. Does cowbird parasitism increase predation risk to American Redstart nests? Oikos 118:1035-1043.

HAUBER, M. E. 2002. Is reduced clutch size a cost of parental care in Eastern Phoebes (Sayornis phoebe)? Behavioral Ecology and Sociobiology 51:503-509.

HAuber, M. E. 2003. Egg-capping is cost paid by hosts of interspecific brood parasities. Auk 120:860-865.

Hill, D. P., AND S. G. SeAlY 1994. Desertion of nests parasitized by cowbirds: have Clay-coloured Sparrows evolved an antiparasitedefence? Animal Behaviour 48:1063-1070.

Hoover, J. P. 2003. Multiple effects of brood parasitism reduce the reproductive success of Prothonotary Warblers Protonotaria citrea. Animal Behaviour 65:923-934.

Hoover, J. P., AND S. K. RoBINSON. 2007. Retaliatory mafia behavior by a parasitic cowbird favors host acceptance of parasitic eggs. Proceedings of the National Academy of Sciences USA 104: 4479-4483.

Hoover, J. P., K. Yasukawa, And M. E. Hauber. 2006. Spatial and temporally structured avian brood parasitism affects the fitness benefits of hosts' rejection strategies. Animal Behaviour 72:881890.
Hosoi, S. A., AND S. I. Rothstein. 2000. Nest desertion and cowbird parasitism: evidences for evolved responses and evolutionary lag. Animal Behaviour 59: 823-840.

Hoy, G., AND J. OTTOW. 1964. Biological and oological studies of the molothrine cowbirds (Icteridae) of Argentina. Auk 81:186-203.

Kattan, G. H. 1997. Shiny Cowbirds follow the 'shotgun' strategy of brood parasitism. Animal Behaviour 43:647-654.

Kosciuch, K. L., AND B. K. SANDERCOCK. 2008. Cowbird removal unexpectedly increases productivity of a brood parasite and the songbird host. Ecological Applications 18:537-548.

Kosciuch, K. L., Parker, T. H. and B. K. SAndercock. 2006. Nest desertion by a cowbird host: an antiparasitic behavior or a response to egg loss? Behavioral Ecology 17:917-924.

Lichtenstein, G. 2001. Selfish begging by Screaming Cowbirds, a mimetic brood parasite of the Bay-winged Cowbird. Animal Behaviour 61:1151-1158.

Llambías, P., V. Ferretti, and J. C. Reboreda. 2006. Egg discrimination and sex-specific pecking behaviour in parasitic cowbirds. Ethology 112:1128-1135.

Lorenzana, J. C., And S. G. Sealy. 1999. A meta-analysis of the impact of parasitism by the Brown-headed Cowbird on its hosts. Studies in Avian Biology 18:241-253.

MARTIN, T. E. 1993. Nest predation and nest sites: new perspectives on old patterns. BioScience 43:523-532.

Martin, T. E., J. Scott, And C. Menge. 2000. Nest predation increases with parental activity: separating nest sites and parental activity effects. Proceedings of the Royal Society of London B 267:2287-2293.

MAson, P. 1980. Ecological and evolutionary aspects of host selection in cowbirds. Ph.D. dissertation, University of Texas, Austin, TX.

Mason, P. 1986. Brood parasitism in a host generalist, the Shiny Cowbird: II. Host selection. Auk 103:61-69.

Massoni, V., AND J. C. ReBoredA. 1998. Costs of brood parasitism and the lack of defenses on the Yellow-winged Blackbird-Shiny Cowbird system. Behavioral Ecology and Sociobiology 42:273-280.

Massoni, V., AND J. C. Reboreda 2002. A neglected cost of brood parasitism: egg punctures by Shiny Cowbirds during inspection of potential host nests. Condor 104:407-412.

Mermoz, M. E., and J. C. Reboreda. 1998. Nesting success in Brown-and-yellow Marshbirds: effects of timing of parasitism, nest site, and brood parasitism. Auk 115:871-878.

Moksnes, A., E. Røskaft. 1989. Adaptations of Meadow Pipits to parasitism by the Common Cuckoo. Behavioral Ecology and Sociobiology 24:25-30.

ORTEGA, C. P. 1998. Cowbirds and other brood parasites. University of Arizona Press, Tucson.

PAyne, R. B., AND L. L. PAYNe. 1998. Brood parasitism by cowbirds: risks and effects on reproductive success and survival in indigobirds. Behavioral Ecology 9:64-73.

PeER, B. D. 2006. Egg destruction and egg removal by avian brood parasites: adaptiveness and consequences. Auk 123:16-22.

Peer, B. D., And E. K. Bollinger. 1997. Explanations for the infrequent cowbird parasitism on Common Grackles. Condor 99: $151-161$.

Petit, J. L. 1991. Adaptive tolerance of cowbird parasitism by Prothonotary Warblers: a consequence of nest-site limitation? Animal Behaviour 41:425-432.

R Development Core Team [online]. 2008. R: A language and environment for statistical computing. R Foundation for Statistical Computing, Vienna, Austria. <http://www.R-project.org> (15 October 2008).

Reboreda, J. C., M. E. Mermoz, V. Massoni, A. A. Astié, And F. L. RABUfFETTI. 2003. Impacto del parasitismo de cría del Tordo 
Renegrido (Molothrus bonariensis) sobre el éxito reproductivo de sus hospedadores. Hornero 18:77-88.

RothsteIn, S. I. 1982. Mechanisms of avian egg recognition: which egg parameters elicit responses by rejecter species? Behavioral Ecology and Sociobiology 11:229-239.

RothSTEIN, S. I. 1990. A model system for coevolution: avian brood parasitism. Annual Review of Ecology and Systematics 21:481508.

SAS Institute. 1998. StatView user's guide. Version 5.0. SAS Institute, Inc., Cary, NC.

SeALY, S. G. 1992. Removal of Yellow Warbler eggs in association with cowbird parasitism. Condor 94:40-54.

Smith, J. N. M., M. J. Taitt, L. Zanette, And I. H. Myers-Smith. 2003. How do Brown-headed Cowbirds (Molothrus ater) cause nest failures in Song Sparrows (Melospiza melodia)? A removal experiment. Auk 120:772-783.

Stake, M. M., AND D. A. Cimprich. 2003. Using video to monitor predation at Black-capped Vireo nests. Condor 105:348-357.
Strausberger, B. M., And D. E. Burhans. 2001. Nest desertion by Field Sparrows and its possible influence on the evolution of cowbird behavior. Auk 118:770-776.

Tewksbury, J. J., T. E. Martin, S. J. Hejl, M. J. Kuehn, and J. W. JENKINS. 2002. Parental care of a cowbird host: caught between the costs of egg-removal and nest predation. Proceedings of the Royal Society of London B 269:423-429.

Trine, C. L. 2000. Effects of multiple parasitism on cowbird and Wood Thrush nesting success, p. 135-144. In J. N. M. Smith, T. L. Cook, S. I. Rothstein, S. K. Robinson, and S. G. Sealy [EDS.], Ecology and management of cowbirds and their hosts. University of Texas Press, Austin.

White, G. C., AND K. P. Burnham. 1999. Program MARK: survival estimation from populations of marked animals. Bird Study 46 Suppl.:120-138.

ZanetTe, L., D. T. Haydon, J. N. M. Smith, M. J. Taitt, and M. Clinchy. 2007. Reassessing the cowbird threat. Auk 124:210 223. 